\title{
Vaccinia Virus Study
}

National Cancer Institute

\section{Source}

National Cancer Institute. Vaccinia Virus Study. NCI Thesaurus. Code C29884.

Clinical Vaccinia Virus Studies employ vaccinia virus as an attenuated agent or as a vector for gene transfer. In attenuated form, Vaccinia virus can be used for protection ag ainst smallpox virus (variola) and is a highly effective immunizing agent. When genetically altered to contain human genes, Vaccinia virus can be used in cancer immunotherapy to induce immune protection against some forms of cancers. ( $\mathrm{NClO4}$ ) 